\title{
Aerotolerance and multilocus sequence typing among Campylobacter jejuni strains isolated from humans, broiler chickens, and cattle in Miyazaki Prefecture, Japan
}

\author{
Savek KIATSOMPHOB ${ }^{1,2)}$, Takako TANIGUCHI ${ }^{3)}$, Elpita TARIGAN ${ }^{3)}$, \\ Khin Maung LATT $^{2)}$, Byeonghwa JEON ${ }^{4)}$ and Naoaki MISAWA ${ }^{2,3) *}$ \\ ${ }^{1)}$ Graduate School of Medicine and Veterinary Medicine, University of Miyazaki, 5200 Kihara-kiyotakecho, \\ Miyazaki 889-1692, Japan \\ 2)Laboratory of Veterinary Public Health, Department of Veterinary Medical Science, Faculty of Agriculture, \\ University of Miyazaki, 1-1 Gakuenkibanadai-nishi, Miyazaki 889-2192, Japan \\ ${ }^{3)}$ Center for Animal Disease Control, University of Miyazaki, 1-1 Gakuenkibanadai-nishi, Miyazaki 889-2192, \\ Japan \\ ${ }^{4)}$ School of Public Health, University of Alberta, Edmonton, AB, T6G 1C9, Canada
}

J. Vet. Med. Sci.

81(8): 1144-1151, 2019

doi: 10.1292/jvms.19-0228

Received: 26 April 2019

Accepted: 2 June 2019

Advanced Epub: 3 July 2019

\begin{abstract}
Campylobacter jejuni is one of the leading causes of human gastroenteritis in Japan. As chickens and cattle are common reservoirs for $C$. jejuni, this microaerophilic, stress-sensitive bacterium can overcome and survive various stress conditions during zoonotic transmission, particularly foodborne, to humans. How C. jejuni overcomes stress conditions is, however, unclear. In the present study, 70 C. jejuni strains isolated from various sources ( 26 human, 20 broilers, and 24 cattle isolates) in Miyazaki, Japan, from 2010 to 2012, were subjected to multilocus sequence typing (MLST) and aerotolerance testing (aerobic shaking at $200 \mathrm{rpm}$ ). The results demonstrated that $C$. jejuni strains from Miyazaki belonged to 12 clonal complexes (CCs) and 43 sequence types (STs). CC-21 and CC-460 were mainly detected in human clinical strains. Most tested strains were aerotolerant, and only one (1.4\%) was deemed sensitive to aerobic stress. Approximately $40 \%$ strains survived the 24-hr vigorous aerobic shaking at $200 \mathrm{rpm}$, and these hyper-aerotolerant strains were more prevalent in broiler and cattle isolates than in human isolates. Phylogenetic analysis divided the strains into five clusters, each showing a different pattern of host association. Thus, we have demonstrated for the first time that C. jejuni strains with increased tolerance to aerobic stress are highly prevalent in broilers and cattle in Miyazaki, Japan, and that certain clonal populations are frequently implicated in human infection in this area.

KEY WORDS: aerotolerance, Campylobacter jejuni, Japan isolate, multilocus sequence typing (MLST)
\end{abstract}

Campylobacter jejuni is a leading cause of bacterial gastroenteritis in humans worldwide [13]. C. jejuni is a gram-negative, rod spiral-shaped, microaerophilic bacterium found in the gastrointestinal tracts of various animals [16]. In particular, poultry and cattle are considered as the common sources for human infection $[17,36]$. C. jejuni can also be isolated from farms and natural environments $[8,10,18]$. The common clinical symptoms of campylobacteriosis include bloody diarrhea, fever, and abdominal pain [6]. In Japan, approximately 2,000 cases of campylobacteriosis have been reported annually since 1982 [12], and the number of cases detected between 1991 and 2008 reveals no evidence of decrease when compared to previous domestic reports [29].

As $C$. jejuni is zoonotically transmitted from animals to humans mainly via foodborne routes, the survival of $C$. jejuni under stress conditions outside the host animal is an important factor for its transmission to humans [5]. As a microaerophilic bacterium, C. jejuni requires low oxygen levels for growth [41], and high levels of atmospheric oxygen may induce oxidative stress owing to the generation of reactive oxygen species (ROS) [15]. Although a limited number of ROS detoxification enzymes are expressed in $C$. jejuni $[4,31]$, some strains are aerotolerant (AT) and may efficiently survive under aerobic conditions. Thus, the AT $C$. jejuni strains may pose serious risks of food contamination and human infection $[19,25,34]$. According to a study from Canada, approximately $35.7 \%$ of $C$. jejuni isolates from retail chicken meat were found to be highly tolerant to aerobic conditions [25]. $C$. jejuni strains with increased aerotolerance survived longer in chicken meat than the strains deemed sensitive to aerobic conditions [26]. To date, however, aerotolerance in C. jejuni has never been investigated in Japan. 
Among the several molecular techniques available for the genotyping of $C$. jejuni, multilocus sequence typing (MLST) based on variations in the sequences of seven housekeeping genes in C. jejuni is frequently used for epidemiological studies in Japan and other countries $[1,3,11,28,29,38,39]$. In the present study, we performed MLST analysis of $C$. jejuni strains isolated from three different sources (i.e., broiler chickens, cattle, and humans) in Miyazaki, Japan. We also measured the levels of aerotolerance among the strains examined. To our knowledge, this is the first study to evaluate aerotolerance among C. jejuni strains in Japan.

\section{MATERIALS AND METHODS}

\section{Bacterial strains and culture conditions}

A total of 70 strains of $C$. jejuni isolated from animal sources (44 strains) and humans (26 strains) were examined. Twenty strains were isolated from the cecal contents of broilers collected at processing plants located in Miyazaki Prefecture, Japan, during 2010-2012. In addition, 24 strains were isolated from fecal samples of cattle, including dairy cows and beef, at Miyakonojo meat inspection center, Miyazaki, Japan in 2012. A total of 26 human-derived strains were isolated from human sporadic cases of uncomplicated enteritis in clinical laboratories in Miyazaki Prefecture during 2010-2011. The bacterial strains obtained were routinely cultured on Blood Agar Base No. 2 (Oxoid, Hampshire, U.K.) supplemented with 5\% defibrinated horse blood (Nippon Biotest Laboratories, Tokyo, Japan) at $42^{\circ} \mathrm{C}$ for $48 \mathrm{hr}$ under microaerophilic conditions $\left(80 \% \mathrm{~N}_{2}, 10 \% \mathrm{CO}_{2}, 5 \% \mathrm{O}_{2}\right.$, and $5 \% \mathrm{H}_{2}$ ). The collected strains were stored in Brucella broth (BD Bioscience, Billerica, MD, U.S.A.) containing 5\% (v/v) glycerol (Wako Pure Chemical, Osaka, Japan) at $-80^{\circ}$ C. C. jejuni strains were confirmed with specific polymerase chain reaction (PCR), as previously described [40].

\section{DNA isolation}

The bacterial DNA was extracted as previously described [22]. Some bacterial cells were suspended in $25 \mu l$ of sterilized distilled water and treated with $25 \mu l$ of $50 \mathrm{mM}$ sodium hydroxide $(\mathrm{NaOH})$. The suspended bacterial cells were heated at $95^{\circ} \mathrm{C}$ for $5 \mathrm{~min}$ and treated with $4 \mu \mathrm{l}$ of $1 \mathrm{M}$ Tris- $\mathrm{HCl}(\mathrm{pH} 7.5)$ for neutralization. The suspension was centrifuged at $8,000 \times g$ and $4^{\circ} \mathrm{C}$ for $5 \mathrm{~min}$. The supernatant was collected and stored at $-20^{\circ} \mathrm{C}$ until analysis of genomic DNA.

\section{Multilocus sequence typing}

MLST analysis of C. jejuni was performed according to the guidelines on the Campylobacter PubMLST (http://pubmlst.org/ campylobacter/) and a previous report [11]. The seven housekeeping genes $\operatorname{asp} A, g \ln A, g l t A, g l y A, p g m, t k t$, and uncA were sequenced in our laboratory. PCR was performed using Taq DNA polymerase (Qiagen, Hilden, Germany), and the PCR products were purified with illustra ExoStar 1-Step (GE Healthcare, Buckinghamshire, U.K.). The sequencing reaction was performed with BigDye terminator v3.1 Cycle Sequencing Kits (Applied Biosystems, Austin, TX, U.S.A.), and the samples were run on a 3130 Genetic analyzer (Applied Biosystems). The sequences were analyzed using the Campylobacter PubMLST Database. Sequence types (STs) and clonal complexes (CCs) of isolates were determined according to the Campylobacter PubMLST. The novel alleles and STs were submitted to Campylobacter PubMLST and termed as new STs. The isolate clusters were visualized with a neighborjoining tree using the neighbor-joining algorithm implementation using PHYLOViZ 2.0 based on the seven allelic profiles [23, 35].

\section{Aerotolerance testing}

Aerotolerance testing was performed as per a previous report [25] with some modifications. In brief, C. jejuni strains were cultivated in Nutrient Broth No. 2 (Oxoid) with 1.5\% Bacto Agar (BD Biosciences) at $42^{\circ} \mathrm{C}$ for 18 hr under microaerophilic conditions. The cells were harvested and the absorbance at $550 \mathrm{~nm}$ was adjusted to 0.05 using Nutrient Broth No. 2. The bacterial suspension was then incubated at $37^{\circ} \mathrm{C}$ and $200 \mathrm{rpm}$ under aerobic conditions. Samples were obtained at 0,12 , and $24 \mathrm{hr}$ for serial dilutions and counting of culturable cells. C. jejuni was considered as aero-sensitive (AS) if the cells grew under aerobic atmosphere with shaking at $200 \mathrm{rpm}$ until $12 \mathrm{hr}$. The strains that grew for 12-24 hr were considered as AT, while those that grew for more than $24 \mathrm{hr}$ under aerobic conditions were classified as hyper-aerotolerant (HAT) [25]. Three individual runs of the same experiment were performed.

\section{RESULTS}

\section{MLST analysis of C. jejuni isolates from various sources}

A total of 70 isolates from various sources (broilers, cattle, and humans) in Miyazaki, Japan, acquired between 2010 and 2012 were subjected to MLST analysis. As a result, 70 strains were classified into 43 STs within 12 CCs; however, two STs were unassignable to any CC (Table 1). The dominant CCs included CC-21 ( $\mathrm{n}=17 ; 24.3 \%)$, CC-460 ( $\mathrm{n}=14 ; 20 \%)$, and CC-464 ( $\mathrm{n}=8$; $11.4 \%$ ), and two CCs (CC-45 and CC-48) comprised only one isolate (Table 1). The dominant CCs in the human isolates were CC-21 and CC-460, whereas those in the cattle isolates were CC-460 and CC-464 (Table 1). The broiler isolates were evenly distributed among the CCs, and the unassignable CCs were uniquely isolated from broilers (Table 1). These results show that the dominant CCs varied depending on the source.

\section{Aerotolerance of C. jejuni isolates from Miyazaki}

The aerotolerance of $C$. jejuni was determined through their cultivation under aerobic conditions at $200 \mathrm{rpm}$ for $24 \mathrm{hr}$. Among 
Table 1. Multilocus sequence typing of Campylobacter jejuni isolates from different sources in Miyazaki, Japan in 2010-2012

\begin{tabular}{|c|c|c|c|c|c|c|c|c|c|c|c|}
\hline \multirow{2}{*}{$\begin{array}{l}\text { Clonal complex } \\
\text { (No. of isolate) }\end{array}$} & \multirow{2}{*}{$\begin{array}{l}\text { Sequence } \\
\text { type }^{\text {a) }}\end{array}$} & \multicolumn{3}{|c|}{ Source } & \multirow{2}{*}{ Total } & \multirow{2}{*}{$\begin{array}{l}\text { Clonal complex } \\
\text { (No. of isolate) }\end{array}$} & \multirow{2}{*}{$\begin{array}{l}\text { Sequence } \\
\text { type }^{\text {a) }}\end{array}$} & \multicolumn{3}{|c|}{ Source } & \multirow{2}{*}{ Total } \\
\hline & & Human & Broiler & Cattle & & & & Human & Broiler & Cattle & \\
\hline \multirow[t]{4}{*}{ CC-21 (17) } & ST-21 & 1 & - & - & 1 & \multirow[t]{4}{*}{ CC-607 (5) } & ST-607 & - & 1 & - & 1 \\
\hline & ST-50 & 2 & 1 & 2 & 5 & & ST-1707 & - & 1 & - & 1 \\
\hline & ST-4253 & 9 & - & - & 9 & & ST-6206 & - & - & 1 & 1 \\
\hline & ST-4526 & - & 2 & - & 2 & & ST-6488 & - & - & 2 & 2 \\
\hline \multirow[t]{9}{*}{ CC-460 (14) } & ST-113 & - & - & 1 & 1 & \multirow[t]{4}{*}{ CC-353 (4) } & ST-2905 & - & 1 & - & 1 \\
\hline & ST-460 & - & 1 & - & 1 & & ST-6207 & - & - & 1 & 1 \\
\hline & ST-5255 & - & 1 & - & 1 & & ST-6473 & - & - & 1 & 1 \\
\hline & ST-6083 & - & 1 & - & 1 & & ST-6492 & - & - & 1 & 1 \\
\hline & ST-6472 & - & - & 2 & 2 & \multirow[t]{3}{*}{ CC-354 (4) } & ST-6084 & - & 1 & - & 1 \\
\hline & ST-6474 & - & - & 1 & 1 & & ST-6470 & - & - & 1 & 1 \\
\hline & ST-6491 & - & - & 1 & 1 & & ST-6471 & - & - & 2 & 2 \\
\hline & ST-6568 & 3 & - & - & 3 & \multirow[t]{2}{*}{ CC-22 (3) } & ST-22 & 1 & - & - & 1 \\
\hline & ST-6570 & 3 & - & - & 3 & & ST-1739 & 1 & - & - & 1 \\
\hline \multirow[t]{5}{*}{ CC-464 (8) } & ST-464 & - & 1 & - & 1 & & ST-4038 & - & - & 1 & 1 \\
\hline & ST-4389 & - & 2 & 2 & 4 & \multirow[t]{2}{*}{ CC-42 (3) } & ST-42 & 2 & - & - & 2 \\
\hline & ST-5268 & 1 & - & - & 1 & & ST-517 & - & - & 1 & 1 \\
\hline & ST-6209 & - & - & 1 & 1 & CC-61 (2) & ST-61 & 2 & - & - & 2 \\
\hline & ST-6486 & - & - & 1 & 1 & CC-45 (1) & ST-6569 & 1 & - & - & 1 \\
\hline \multirow[t]{4}{*}{ CC-52 (5) } & ST-52 & - & 2 & - & 2 & $\mathrm{CC}-48$ (1) & ST-3503 & - & 1 & - & 1 \\
\hline & ST-4265 & - & 1 & - & 1 & \multirow[t]{2}{*}{ UA (3) } & ST-2156 & - & 1 & - & 1 \\
\hline & ST-6479 & - & - & 1 & 1 & & ST-6085 & - & 2 & - & 2 \\
\hline & ST-6480 & - & - & 1 & 1 & Total & & 26 & 20 & 24 & 70 \\
\hline
\end{tabular}

a) Novel STs found in this study are shown in bold. CC, clonal complexes; ST, Sequence type, UA represents the sequence types unassigned to any CCs.

Table 2. Aerotolerant screening of Campylobacter jejuni isolates from different sources in Miyazaki, Japan in 2010-2012

\begin{tabular}{lccll}
\hline & Human & Broiler & Cattle & Total \\
\hline Aero-sensitive & 0 & $1(5 \%)$ & 0 & $1(1.4 \%)$ \\
Aerotolerant $^{\mathrm{a})}$ & $22(84.6 \%)$ & $7(35 \%)$ & $12(50 \%)$ & $41(58.6 \%)$ \\
Hyper-aerotolerant $^{\mathrm{b})}$ & $4(15.4 \%)$ & $12(60 \%)$ & $12(50 \%)$ & $28(40 \%)$ \\
Total & 26 & 20 & 24 & 70 \\
\hline
\end{tabular}

a) Aerotolerant, viable after aerobically incubated for $12 \mathrm{hr}$; b) Hyper-aerotolerant, viable after aerobically incubated for $24 \mathrm{hr}$.

the 70 C. jejuni isolates, 28 (40\%) were deemed HAT and 41 (58.6\%) were AT; only one (1.4\%) strain was found to be AS, owing to its inability to thrive under aerobic shaking conditions after $12 \mathrm{hr}$ (Table 2). HAT strains were highly prevalent, mainly in $C$. jejuni isolates from cattle and broilers; however, AT strains were predominant among human isolates (Fig. 1 and Table 2). The AS strain was isolated from a broiler (Fig. 1 and Table 2). Although HAT strains were well distributed in most CCs, all strains in CC354 were found to be HAT (Fig. 2). High prevalence of AT C. jejuni strains was detected in the major CCs (CC-21 and CC-460), and CC-464 comprised C. jejuni strains with different levels of aerotolerance (Fig. 2). Thus, the prevalence of HAT C. jejuni was affected by the source and CC.

\section{Phylogenetic relationships between C. jejuni isolates in Miyazaki}

Based on the allelic profiles of MLST, a neighbor-joining tree was generated for the analysis of the phylogenetic relationships among C. jejuni strains. The isolates were clustered into five subgroups with a CC-61 singleton, which did not belong to any subgroup (Fig. 3). Clusters V and IV comprised C. jejuni isolates from all three different sources (i.e., broilers, cattle, and humans). However, human clinical isolates were predominant in clusters V and IV (Fig. 3A); the strains in cluster V mostly belonged to CC-21, while those in cluster IV were mostly included in CC-22 and CC-42 (Fig. 3A). Cluster I was also associated with human clinical isolates, but the predominant strains in this cluster were from cattle, suggesting that cattle are the dominant source for cluster I (Fig. 3A). Clusters II and III were primarily associated with animal isolates; only one human isolate was part of clusters II and III. In particular, cluster II solely included the isolates from broilers and cattle (Fig. 3A). These results demonstrate that $C$. jejuni strains were phylogenetically related based on the source and that some clusters were closely related to human infection.

HAT C. jejuni strains were distributed among the five clusters; however, cluster II comprising only animal isolates exhibited the highest prevalence of HAT strains (Fig. 3A and 3B). The prevalence of HAT C. jejuni in cluster I was similar to that in cluster III, while the distribution of sources differed between the two clusters (Fig. 3A and 3B). These results suggest that HAT strains may be more frequently associated with animal isolates than human clinical strains. 
$\mathbf{A}$

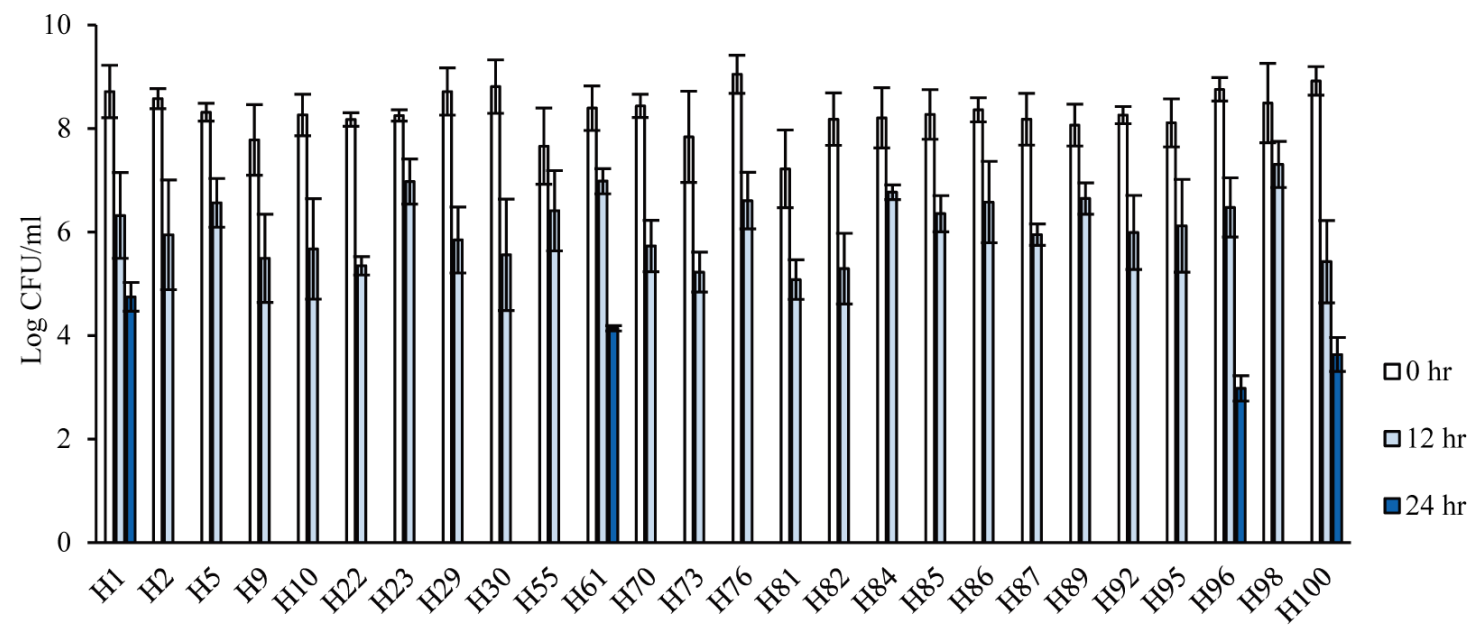

B

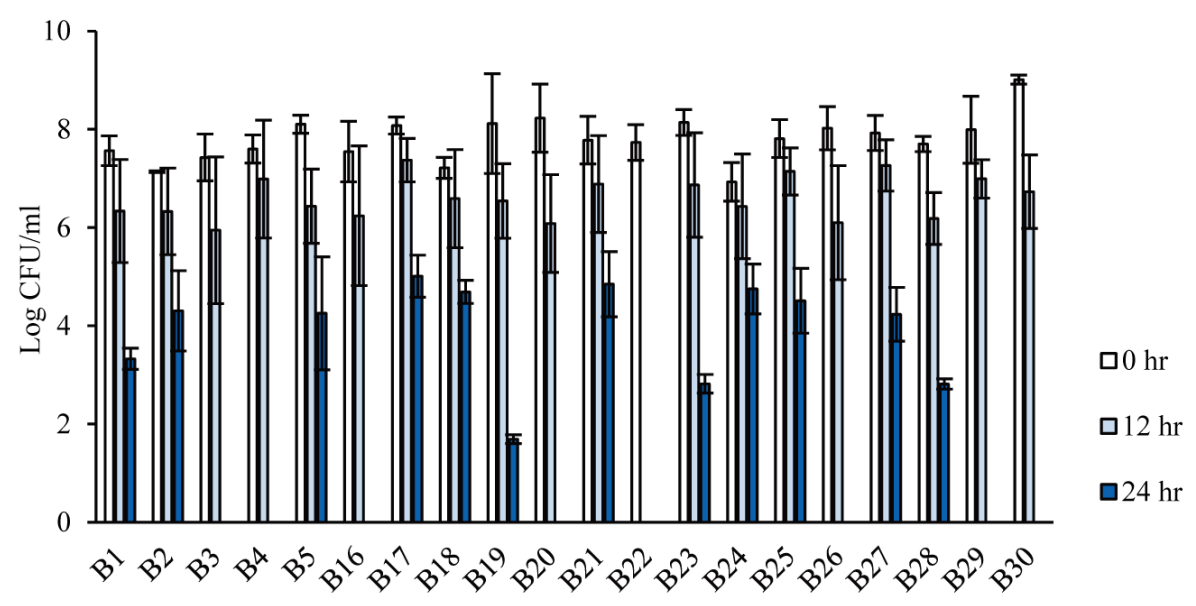

$\mathbf{C}$

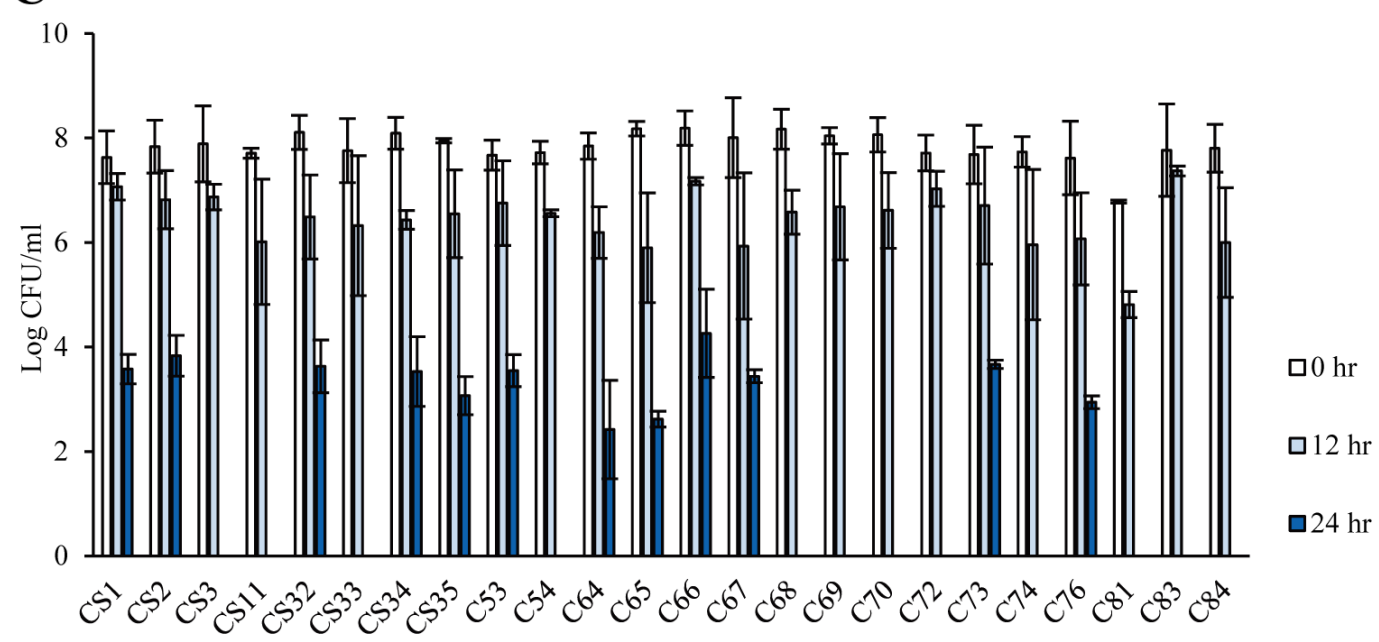

Fig. 1. The aerotolerance levels of Campylobacter jejuni strains isolated from different sources in Miyazaki, Japan. Culturable cells were counted after incubation for 0,12 , and $24 \mathrm{hr}$ at $37^{\circ} \mathrm{C}$ and $200 \mathrm{rpm}$ under aerobic conditions. Isolates from humans (A), broiler chickens (B), and cattle (C). The results show the means and standard deviations of three individual experiments. 


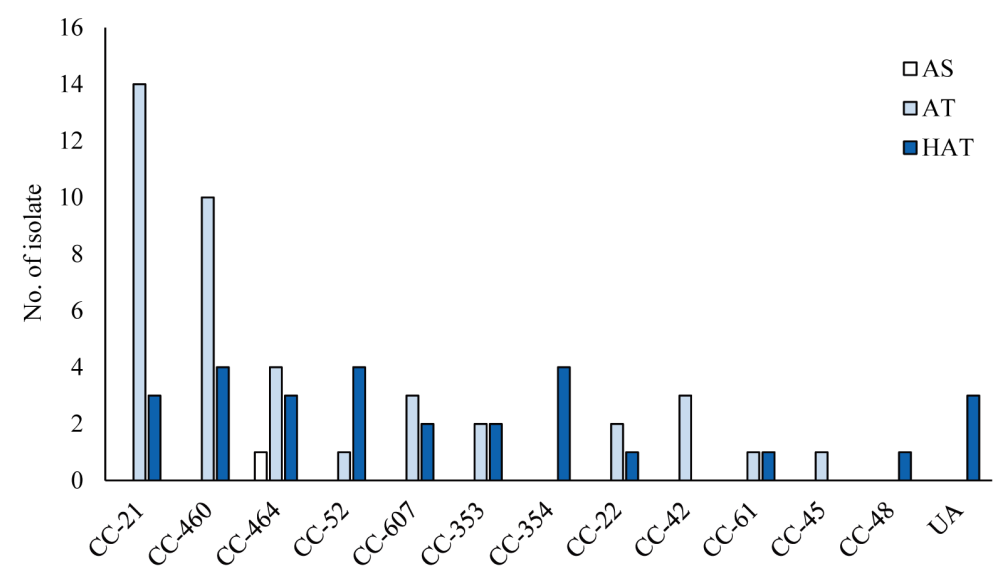

Fig. 2. Frequency distribution of Campylobacter jejuni clonal complexes (CCs) among strains with different levels of aerotolerance. AS, aerosensitive; AT, aerotolerant; HAT, hyper-aerotolerant. UA represents the sequence types unassigned to any CC.

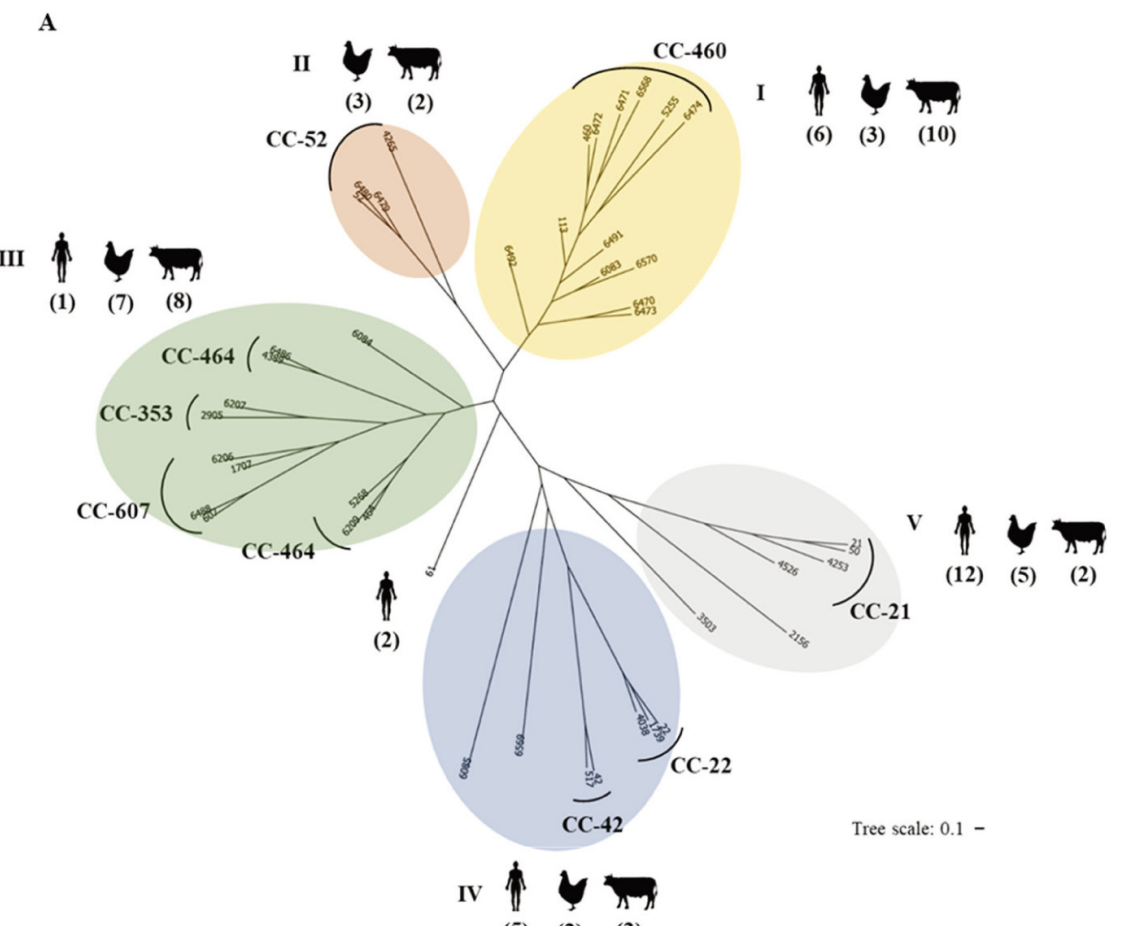

(5) (2) (2)

B

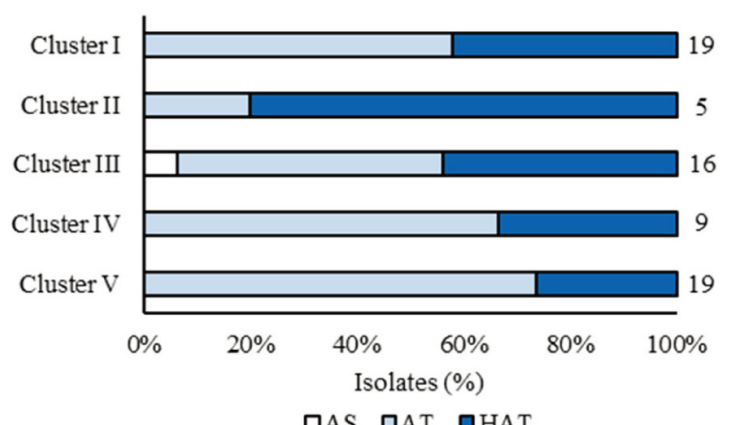

Fig. 3. Phylogenetic analysis of Campylobacter jejuni strains isolated from humans, broilers, and cattle in Miyazaki, Japan. (A) A neighbor-joining tree of Campylobacter jejuni generated from the multilocus sequence typing data showing relationships among the 70 Campylobacter jejuni strains examined. The sequence type numbers are shown, and the numbers of isolates from different sources are indicated in parentheses. (B) The percentage distribution of each cluster based on aerotolerance. AS, aero-sensitive; AT, aerotolerant; HAT, hyper-aerotolerant. The numbers indicate the number of isolates in each group. 


\section{DISCUSSION}

The results of the MLST analysis of 70 C. jejuni strains from various sources in Miyazaki, Japan, revealed CC-21 as the major CC (Table 1). Previous reports from Japan have also indicated CC-21 as the most common CC [2, 3, 28, 29], possibly owing to its association with strains from various sources [14, 37]. CC-21 is widely spread in Japan, even in Kyushu, which is separated from the main island of Honshu. According to a previous study by Asakura et al. (2012), ST-4526 within CC-21 is unique to Japan, and the strains in this ST express filamentous hemagglutination domain protein (FHA) and increased antibiotic resistance [3]. In the present study, two C. jejuni strains belonging to ST-4526 were isolated from broilers (Table 1), indicative of the presence of ST-4526 in Miyazaki. ST-4253 was predominant in human isolates, consistent with the finding of a recent report that indicated the wide spread of ST-4253 in Japan. The strains in ST-4253 have superior ability to colonize chicken intestine [2]; however, we were unable to identify any isolates from broilers that belonged to ST-4253 (Table 1). In Japan, CC-21 and CC-48 are the major CCs in C. jejuni isolates from broilers [29]. Interestingly, we found that only one isolate belonged to CC-48, and broiler isolates were widely distributed in various CCs without any major ones (Table 1). While CC-460 and CC-464 were the major CCs associated with cattle isolates in the present study (Table 1), a previous study reported CC-21 as the major clone for cattle isolates [3]. Another study conducted in Japan found CC-460 and CC-464 as the major CCs in human and chicken isolates, followed by CC-21 [28]. Our data and a previous report suggest that CC-460 and CC-464 are expanding in Japan.

The phylogenetic analysis conducted herein divided C. jejuni isolates in Miyazaki into five clusters (Fig. 3A). Each cluster showed variations in the source of isolation and level of $C$. jejuni aerotolerance. More than $50 \%$ of all isolates ( $\mathrm{n}=38$ ) belonged to clusters I and V. In cluster I, cattle isolates accounted for the major proportion, suggesting that $C$. jejuni strains from cattle in this cluster may be responsible for human infection and that broilers appear to be the primary source for human infection in cluster $\mathrm{V}$ (Fig. 3A). Unlike the strong association between clusters IV and V and human clinical isolates, clusters II and III mainly comprised animal isolates (Fig. 3A), indicative of the association of different phylogenetic groups with preferred hosts for C. jejuni. The CC52 assigned in cluster II in this study mainly comprised animal isolates, while other reports showed that the strains in CC-52 were mostly isolated from humans. These differences may be influenced by the regions studied [24, 32, 33].

In the present study, we also determined the level of aerotolerance in the 70 strains of $C$. jejuni from various sources. Interestingly, high prevalence of HAT strains was observed among $C$. jejuni isolated from broilers and cattle, whereas AT strains were predominant in human clinical isolates (Table 2). A previous study from Canada showed that $35.7 \%$ of $C$. jejuni isolates from retail raw chicken were HAT. In the present study, we similarly observed $40 \%$ HAT strains among $C$. jejuni isolates from various sources (Table 2), suggesting that the overall proportion of HAT strains would be similar between the two countries [25]. However, further experiments are warranted to compare the prevalence using $C$. jejuni strains isolated from the same type of sample (i.e., retail chicken meat).

The CCs that had more than three HAT strains of $C$. jejuni included CC-460, CC-464, and CC-354 (Fig. 2). These results are quite different from the Canadian study, wherein HAT C. jejuni strains from retail raw chicken predominantly belonged to CC-21 [25]. In this study, CC-21 was the dominant clone but contained relatively low numbers of HAT C. jejuni ( $\mathrm{n}=3$ from 17 isolates in CC-21) (Fig. 2). Although the reason underlying this difference is unclear, the prevalence of HAT strains may be affected by the source and perhaps the region of origin. We performed aerotolerance testing at $37^{\circ} \mathrm{C}$ unlike $42^{\circ} \mathrm{C}$ by $\mathrm{Oh}$ et al. [25], owing to the use of strains from humans, cattle, and chickens. As the levels of aerotolerance were evaluated based on the growth ability of the bacteria, not by proliferation under aerobic conditions, the most appropriate incubation temperature for the testing is still debatable.

Our results confirmed that HAT C. jejuni were highly prevalent among the strains isolated from animals such as broilers and cattle (Table 2), suggesting that hyper-aerotolerance may play a role in the colonization of $C$. jejuni in the gastrointestinal tracts of animals. HAT C. jejuni strains harbor more virulence genes than AS strains [26]. In the same study, most of the tested virulence genes were involved in $C$. jejuni adhesion to epithelial cells and colonization of chicken intestine; thus, HAT C. jejuni may effectively colonize chicken intestine $[7,25]$. In addition, aerotolerance was closely related to oxidative stress defense in $C$. jejuni, and the genes involved affected $C$. jejuni colonization in the chicken intestine [30]. HAT $C$. jejuni strains presumably possess greater ability to resist oxidative stress and exhibit colonization; however, this hypothesis requires future experimental validation.

Oh et al. (2018) observed high prevalence (53.7\%) of HAT among human clinical strains of $C$. jejuni in Canada. These authors also investigated the tolerance of $C$. jejuni to other stress conditions, and the multi-stress-tolerant strains were the main cause of human infection $[9,21,27]$. The high prevalence of HAT C. jejuni in cattle and broiler isolates may potentially be a public health concern. As C. jejuni could survive the oxidative stress in atmospheric environment during transmission to humans [20], the high prevalence of HAT $C$. jejuni in broilers and cattle may pose a high risk of food contamination and human infection. However, aerotolerance is not the sole prominent determinant affecting human transmission. In addition, our study showed that the cluster with the highest proportion of HAT strains was mainly associated with animals (Fig. 3A and 3B), and that the proportion of HAT C. jejuni in human clinical samples was relatively low (Table 2). Whether the discrepancy was related to the geographical differences between Canada and Japan or if the infection routes for C. jejuni differ between the two countries is questionable. More information is also needed about the tolerance of human clinical strains to other stress conditions that might affect their transmission to humans via food. To our knowledge, this is the first reported study on the aerotolerance of $C$. jejuni isolates in Japan. Further studies on stress tolerance are needed to clarify how this stress-sensitive bacterial pathogen survives and is zoonotically transmitted to humans.

ACKNOWLEDGMENT. The work was supported by grants for a project on Core-to-Core Program, Asia-Africa Science Platforms by the Japan Society for the Promotion of Science (JSPS). 


\section{REFERENCES}

1. Ahmed, M. U., Dunn, L. and Ivanova, E. P. 2012. Evaluation of current molecular approaches for genotyping of Campylobacter jejuni strains. Foodborne Pathog. Dis. 9: 375-385. [Medline] [CrossRef]

2. Asakura, H., Taguchi, M., Ekawa, T., Yamamoto, S. and Igimi, S. 2013. Continued widespread dissemination and increased poultry host fitness of Campylobacter jejuni ST-4526 and ST-4253 in Japan. J. Appl. Microbiol. 114: 1529-1538. [Medline] [CrossRef]

3. Asakura, H., Brüggemann, H., Sheppard, S. K., Ekawa, T., Meyer, T. F., Yamamoto, S. and Igimi, S. 2012. Molecular evidence for the thriving of Campylobacter jejuni ST-4526 in Japan. PLoS One 7: e48394. [Medline] [CrossRef]

4. Atack, J. M. and Kelly, D. J. 2007. Structure, mechanism and physiological roles of bacterial cytochrome c peroxidases. Adv. Microb. Physiol. 52: 73-106. [Medline] [CrossRef]

5. Begley, M. and Hill, C. 2015. Stress adaptation in foodborne pathogens. Annu. Rev. Food Sci. Technol. 6: 191-210. [Medline] [CrossRef]

6. Blaser, M. J. 1997. Epidemiologic and clinical features of Campylobacter jejuni infections. J. Infect. Dis. 176 Suppl 2: S103-S105. [Medline] [CrossRef]

7. Bolton, D. J. 2015. Campylobacter virulence and survival factors. Food Microbiol. 48: 99-108. [Medline] [CrossRef]

8. Bolton, F. J., Surman, S. B., Martin, K., Wareing, D. R. and Humphrey, T. J. 1999. Presence of Campylobacter and Salmonella in sand from bathing beaches. Epidemiol. Infect. 122: 7-13. [Medline] [CrossRef]

9. Cameron, A., Frirdich, E., Huynh, S., Parker, C. T. and Gaynor, E. C. 2012. Hyperosmotic stress response of Campylobacter jejuni. J. Bacteriol. 194: 6116-6130. [Medline] [CrossRef]

10. Colles, F. M., Jones, K., Harding, R. M. and Maiden, M. C. 2003. Genetic diversity of Campylobacter jejuni isolates from farm animals and the farm environment. Appl. Environ. Microbiol. 69: 7409-7413. [Medline] [CrossRef]

11. Dingle, K. E., Colles, F. M., Wareing, D. R., Ure, R., Fox, A. J., Bolton, F. E., Bootsma, H. J., Willems, R. J., Urwin, R. and Maiden, M. C. 2001 Multilocus sequence typing system for Campylobacter jejuni. J. Clin. Microbiol. 39: 14-23. [Medline] [CrossRef]

12. Enokimoto, M., Kubo, M., Bozono, Y., Mieno, Y. and Misawa, N. 2007. Enumeration and identification of Campylobacter species in the liver and bile of slaughtered cattle. Int. J. Food Microbiol. 118: 259-263. [Medline] [CrossRef]

13. Friedman, C. R., Neiman, J., Wegener, H. C. and Tauxe, R. V. 2000. Epidemiology of Campylobacter jejuni infections in the United States and other industrialised nations. pp. 121-138. In: Campylobacter (Nachamkin, I. and Blaser, M. J. eds.), ASM, Washington, D.C.

14. Gripp, E., Hlahla, D., Didelot, X., Kops, F., Maurischat, S., Tedin, K., Alter, T., Ellerbroek, L., Schreiber, K., Schomburg, D., Janssen, T., Bartholomäus, P., Hofreuter, D., Woltemate, S., Uhr, M., Brenneke, B., Grüning, P., Gerlach, G., Wieler, L., Suerbaum, S. and Josenhans, C. 2011. Closely related Campylobacter jejuni strains from different sources reveal a generalist rather than a specialist lifestyle. BMC Genomics 12: 584 . [Medline] [CrossRef]

15. Gundogdu, O., da Silva, D. T., Mohammad, B., Elmi, A., Wren, B. W., van Vliet, A. H. M. and Dorrell, N. 2016. The Campylobacter jejuni oxidative stress regulator rrpb is associated with a genomic hypervariable region and altered oxidative stress resistance. Front. Microbiol. 7: 2117. [Medline] [CrossRef]

16. Guyard-Nicodème, M., Rivoal, K., Houard, E., Rose, V., Quesne, S., Mourand, G., Rouxel, S., Kempf, I., Guillier, L., Gauchard, F. and Chemaly, M. 2015. Prevalence and characterization of Campylobacter jejuni from chicken meat sold in French retail outlets. Int. J. Food Microbiol. 203: 8-14. [Medline] [CrossRef]

17. Hermans, D., Pasmans, F., Messens, W., Martel, A., Van Immerseel, F., Rasschaert, G., Heyndrickx, M., Van Deun, K. and Haesebrouck, F. 2012. Poultry as a host for the zoonotic pathogen Campylobacter jejuni. Vector Borne Zoonotic Dis. 12: 89-98. [Medline] [CrossRef]

18. Jones, K. 2001. Campylobacter in water, sewage and the environment. J. Appl. Microbiol. 90: 68S-79S. [CrossRef]

19. Karki, A. B., Marasini, D., Oakey, C. K., Mar, K. and Fakhr, M. K. 2018. Campylobacter coli from retail liver and meat products is more aerotolerant than Campylobacter jejuni. Front. Microbiol. 9: 2951. [Medline] [CrossRef]

20. Kim, J. C., Oh, E., Kim, J. and Jeon, B. 2015. Regulation of oxidative stress resistance in Campylobacter jejuni, a microaerophilic foodborne pathogen. Front. Microbiol. 6: 751. [Medline] [CrossRef]

21. Klančnik, A., Vučković, D., Jamnik, P., Abram, M. and Možina, S. S. 2014. Stress response and virulence of heat-stressed Campylobacter jejuni. Microbes Environ. 29: 338-345. [Medline] [CrossRef]

22. Misawa, N., Kawashima, K., Kawamoto, H. and Kondo, F. 2002. Development of a combined filtration-enrichment culture followed by a onestep duplex PCR technique for the rapid detection of Campylobacter jejuni and C. coli in human faecal samples. J. Med. Microbiol. 51: 86-89. [Medline] [CrossRef]

23. Nascimento, M., Sousa, A., Ramirez, M., Francisco, A. P., Carriço, J. A. and Vaz, C. 2017. PHYLOViZ 2.0: providing scalable data integration and visualization for multiple phylogenetic inference methods. Bioinformatics 33: 128-129. [Medline] [CrossRef]

24. Ngulukun, S., Oboegbulem, S. and Klein, G. 2016. Multilocus sequence typing of Campylobacter jejuni and Campylobacter coli isolates from poultry, cattle and humans in Nigeria. J. Appl. Microbiol. 121: 561-568. [Medline] [CrossRef]

25. Oh, E., McMullen, L. and Jeon, B. 2015. High prevalence of hyper-aerotolerant Campylobacter jejuni in retail poultry with potential implication in human infection. Front. Microbiol. 6: 1263. [Medline] [CrossRef]

26. Oh, E., McMullen, L. M., Chui, L. and Jeon, B. 2017. Differential survival of hyper-aerotolerant Campylobacter jejuni under different gas condition. Front. Microbiol. 8: 954. [Medline] [CrossRef]

27. Oh, E., Chui, L., Bae, J., Li, V., Ma, A., Mutschall, S. K., Taboada, E. N., McMullen, L. M. and Jeon, B. 2018. Frequent implication of multistresstolerant Campylobacter jejuni in human infections. Emerg. Infect. Dis. 24: 1037-1044. [Medline] [CrossRef]

28. Ohishi, T., Aoki, K., Ishii, Y., Usui, M., Tamura, Y., Kawanishi, M., Ohnishi, K. and Tateda, K. 2017. Molecular epidemiological analysis of humanand chicken-derived isolates of Campylobacter jejuni in Japan using next-generation sequencing. J. Infect. Chemother. 23: 165-172. [Medline] [CrossRef]

29. Ozawa, M., Hiki, M., Kawanishi, M., Abo, H., Kojima, A., Asai, T. and Hamamoto, S. 2016. Molecular typing of fluoroquinoloneresistant Campylobacter jejuni isolated from boilers in Japan using multilocus sequence typing and pulsed-field gel electrophoresis. Foodborne Pathog. Dis. 13: 1-7. [Medline] [CrossRef]

30. Palyada, K., Sun, Y. Q., Flint, A., Butcher, J., Naikare, H. and Stintzi, A. 2009. Characterization of the oxidative stress stimulon and PerR regulon of Campylobacter jejuni. BMC Genomics 10: 481. [Medline] [CrossRef]

31. Parkhill, J., Wren, B. W., Mungall, K., Ketley, J. M., Churcher, C., Basham, D., Chillingworth, T., Davies, R. M., Feltwell, T., Holroyd, S., Jagels, K., Karlyshev, A. V., Moule, S., Pallen, M. J., Penn, C. W., Quail, M. A., Rajandream, M. A., Rutherford, K. M., van Vliet, A. H., Whitehead, S. and Barrell, B. G. 2000. The genome sequence of the food-borne pathogen Campylobacter jejuni reveals hypervariable sequences. Nature 403: 665-668. [Medline] [CrossRef] 
32. Ragimbeau, C., Schneider, F., Losch, S., Even, J. and Mossong, J. 2008. Multilocus sequence typing, pulsed-field gel electrophoresis, and fla short variable region typing of clonal complexes of Campylobacter jejuni strains of human, bovine, and poultry origins in Luxembourg. Appl. Environ. Microbiol. 74: 7715-7722. [Medline] [CrossRef]

33. Ramonaite, S., Tamuleviciene, E., Alter, T., Kasnauskyte, N. and Malakauskas, M. 2017. MLST genotypes of Campylobacter jejuni isolated from broiler products, dairy cattle and human campylobacteriosis cases in Lithuania. BMC Infect. Dis. 17: 430. [Medline] [CrossRef]

34. Rodrigues, R. C., Pocheron, A. L., Hernould, M., Haddad, N., Tresse, O. and Cappelier, J. M. 2015. Description of Campylobacter jejuni Bf, an atypical aero-tolerant strain. Gut Pathog. 7: 30. [Medline] [CrossRef]

35. Saitou, N. and Nei, M. 1987. The neighbor-joining method: a new method for reconstructing phylogenetic trees. Mol. Biol. Evol. 4: 406-425. [Medline]

36. Sanad, Y. M., Kassem, I. I., Liu, Z., Lin, J., Lejeune, J. T. and Rajashekara, G. 2011. Occurrence of the invasion associated marker (iam) in Campylobacter jejuni isolated from cattle. BMC Res. Notes 4: 570. [Medline] [CrossRef]

37. Sopwith, W., Birtles, A., Matthews, M., Fox, A., Gee, S., Painter, M., Regan, M., Syed, Q. and Bolton, E. 2008. Identification of potential environmentally adapted Campylobacter jejuni strain, United Kingdom. Emerg. Infect. Dis. 14: 1769-1773. [Medline] [CrossRef]

38. Urwin, R. and Maiden, M. C. 2003. Multi-locus sequence typing: a tool for global epidemiology. Trends Microbiol. 11: 479-487. [Medline] [CrossRef]

39. Yabe, S., Higuchi, W., Iwao, Y., Takano, T., Razvina, O., Reva, I., Nishiyama, A. and Yamamoto, T. 2010. Molecular typing of Campylobacter jejuni and C. coli from chickens and patients with gastritis or Guillain-Barré syndrome based on multilocus sequence types and pulsed-field gel electrophoresis patterns. Microbiol. Immunol. 54: 362-367. [Medline] [CrossRef]

40. Yamazaki-Matsune, W., Taguchi, M., Seto, K., Kawahara, R., Kawatsu, K., Kumeda, Y., Kitazato, M., Nukina, M., Misawa, N. and Tsukamoto, T. 2007. Development of a multiplex PCR assay for identification of Campylobacter coli, Campylobacter fetus, Campylobacter hyointestinalis subsp. hyointestinalis, Campylobacter jejuni, Campylobacter lari and Campylobacter upsaliensis. J. Med. Microbiol. 56: 1467-1473. [Medline] [CrossRef]

41. Young, K. T., Davis, L. M. and Dirita, V. J. 2007. Campylobacter jejuni: molecular biology and pathogenesis. Nat. Rev. Microbiol. 5: 665-679. [Medline] [CrossRef] 